\title{
DEPTH CONSTRAINTS ON DILATANCY INDUCED VELOCITY ANOMALIES
}

\author{
Kenneth W. WINKLER and Amos Nur \\ Department of Geophysics, Stanford University, \\ Stanford, California, U.S.A. \\ (Received May 31, 1977; Revised June 13, 1977)
}

\begin{abstract}
Dilatancy, the opening of cracks in rock under applied shear stress, has been proposed as a mechanism to explain seismic velocity anomalies prior to earthquakes. In recent years many studies have been made in search of precursory changes in $V_{p} / V_{s}$, but positive results have been extremely limited. Since dilatancy ind uced velocity anomalies require undersaturation of rock pores, we look carefully at porosity and fluid compressibility within the crust in an effort to determine the conditions that are most favorable for induced velocity anomalies. Simple porositytemperature-pore pressure models of the crust are examined. Various dilatant strain distributions are imposed on the models and in every case the most significant potential for velocity anomalies occurs within the upper 3 to $5 \mathrm{~km}$ of the crust. Low porosity and high temperature at depth have the net effect of giving smaller velocity anomalies than in near surface regions. Actual crustal porosity, pore pressure and strain distributions prior to an earthquake are not well known. Nevertheless, our results suggest that searches for velocity anomalies should be concentrated in the upper few kilometers of the crust where the most significant anomalies are favored to occur.
\end{abstract}

\section{Introduction}

Ever since Nersesov et al. (1969) and SEMENOv (1969) reported seismic velocity anomalies preceding earthquakes in the Garm region of the Soviet Union, seismologists have searched for these anomalies in other areas with the hope of being able to predict earthquakes. AGGARWAL et al. (1973) reported decreases in the ratio of $P$ and $S$ wave velocities prior to earthquakes in the Adirondack region of New York and Talwani et al. (1976) have reported similar behavior in South Carolina. Whiтcomb et al. (1973) reported velocity anomalies preceding the San Fernando earthquake of 1971. A dilatancy-diffusion model was developed (NUR, 1972; ScHoLz et al., 1973; Whitcomb et al., 1973) to explain these velocity changes. According to this model, increasing shear stress in a fluid saturated crust causes the opening of dilatant microcracks (BRACE et al., 1966). These undersaturated cracks reduce $V_{p} / V_{s}$ ( $P$-wave velocity/S-wave velocity) and by increasing the effective confining pressure tend to strengthen the rock (dilatancy hardening). In time, pore fluid from the surrounding rock will diffuse into the dilatant microcracks and increase $V_{p} / V_{s}$ to above its original value. The increasing pore pressure weakens the rock and helps trigger an earthquake. 
Several models have been proposed for dilatancy without fluid flow (e.g., MYachkin et al., 1975; StUART, 1974; BRADY, 1974). The velocity anomalies however, are sensitive even in this case to the presence of water in the crust. Whether the crust contains water or not is not as yet known. We will assume that any existing pore space, aside from the dilatant one, is filled with water.

As a result of the dilatancy diffusion theory, velocity precursors often came to be expected before all earthquakes. As several investigators (ALLEN and HELMBERgER, 1973; BAKUn et al., 1973; Boore et al., 1975) have looked for and failed to find velocity anomalies preceding earthquakes, some seismologists tended to discard in situ dilatancy in total. However, the notion that dilatancy must always lead to velocity anomalies is clearly erroneous: A decrease in $V_{p} / V_{s}$ will occur only when the dilatant pore strain is large enough to cause undersaturation and even when undersaturation occurs, the effective porosity (porosity/aspect ratio) has to be large enough to have a measurable effect on the velocity.

Assuming, as mentioned already, that the crust is water saturated, it follows that the achievement of undersaturation at any depth in the crust depends on the initial pore pressure and the amount of dilatant porosity increase. We assume that dilatancy occurs isothermally, so that at any given temperature the pore increase required for undersaturation is determined by how close the pore fluid is to the liquid-vapor transition pressure (ANDERson and WhITCOMB, 1973; HANKs, 1974; BRACE, 1975). Obviously, lower pore pressure requires a smaller porosity increase.

There are several aspects of the depth dependence of velocity anomalies. First, we must consider three types of porosity. Macrocrack porosity is significant only in the upper few hundred meters (SNow, 1968). Microcrack porosity is significant in the upper $10 \mathrm{~km}$ or so, and pore porosity is approximately constant to great depth (BRACE, 1975). The associated depth dependence of velocity anomalies induced by dilatancy has been characterized by several authors (Scholz et al., 1973; AGGARWAL et al., 1973; ANDerson and Whitcomb, 1975) as limited to 'shallow' earthquakes. Conversely, HADLEY's (1973) experimental results can be interpreted to exclude dilatancy from shallow depths, though the results are not conclusive. Based on more general considerations, GLADWIN and STACEY (1974) concluded that seismic velocities will be strongly sensitive to changing stress only within the upper $10 \mathrm{~km}$ of the crust. This was based on a compilation of many laboratory measurements with the limiting factors being the low porosity and large confining pressures below about $10 \mathrm{~km}$. However, this data did not include the effects of pore fluids on velocity.

Several authors concluded that pore pressure must be low (sub-hydrostatic) to begin with, if mid-crustal dilatancy induced velocity anomalies actually occur (HANKs, 1974; Brace, 1975; BoOKER, 1975). In the last few years, however, a number of studies have looked for and failed to find velocity anomalies associated with earthquakes (Allen and Helmberger, 1973; Bakun et al., 1973; Boore et al., 1975; CRAMER, 1976). The whole issue of whether or not such velocity anomalies really do exist is somewhat clouded at the present. Therefore it seems worthwhile to take a closer look at the potential for dilatancy induced velocity anomalies at various 
depths in the crust. It is important to note that we are not considering the potential for dilatancy. Dilatancy does not necessarily imply an observable velocity anomaly. We are simply going to look at a variety of distributions of dilatant porosity increases in the crust and estimate the velocity anomalies associated with them. We are only interested in whether or not a significant velocity anomaly occurs and the relative magnitude of the anomaly at different depths in the crust. We will look at a range of crustal models and dilatant strain distributions that will represent extremes of actual crustal conditions. Since we obtain similar results in each case we can assume that the real earth will behave the same way.

\section{Analysis: Dilatancy Onset}

We begin with a simple derivation of the change in porosity required to achieve undersaturation in the crust. Let $V_{0}$ be the volume of a unit mass of pore fluid in undilated porous rock. The pore volume increase by dilatancy necessary to cause vapor to appear (assuming isothermal expansion) is

$$
\Delta V=V_{0} \int_{P_{0}}^{P_{t}} \beta \mathrm{d} P
$$

where $\beta$ is the pore fluid compressibility, $P_{0}$ is the initial pore pressure and $P_{t}$ is the liquid-vapor transition pressure. If we replace $\beta$ by the average compressibility $\beta_{\mathrm{av}}$ during expansion, then we have

$$
\Delta V=V_{0} \beta_{\mathrm{av}} \Delta P
$$

Dividing by total rock volume $V_{t}$ we obtain

$$
\Delta \phi=\beta \phi \Delta P,
$$

where $\phi=V_{0} / V_{t}$ is the porosity. The quantity $\Delta \phi$ is the change of porosity required for undersaturation. Ignoring grain compressibility, $\Delta \phi$ is equal to the volumetric rock strain, or the dilatant strain needed for undersaturation, and hence for reduction of $V_{p} / V_{s}$. Equation (3) shows that the required dilatant strain increases with the compressibility of the pore fluid, the porosity of the rock and the initial pore pressure.

In the crust of the earth all three quantities vary with depth. $\Delta P$ increases approximately linearly with depth, $\Delta P \propto z$. Pressure and temperature combine to also increase $\beta_{\mathrm{a} v}$ roughly linearly with depth, $\beta_{\mathrm{a}} \propto z$, as seen in the tables of KenNeDY and Holzer, 1966. Porosity may decrease approximately exponentially with depth, $\phi \propto \mathrm{e}^{-\alpha z}$, as increasing confining pressure closes pores, as will be verified later. Thus a rough estimate for the depth dependence of $\Delta \phi$ is

$$
\Delta \phi \propto z^{2} \mathrm{e}^{-\alpha z}
$$

This is shown qualitatively in Fig. 1. For comparison, we note that the fractional change in porosity will increase with depth, $\Delta \phi / \phi \propto z^{2}$. Equation (4) and Fig. 1, show that the dilatant strain required to cause undersaturation is small and hence easy to achieve, at shallow and deep parts of the crust. In the middle there is a region in 


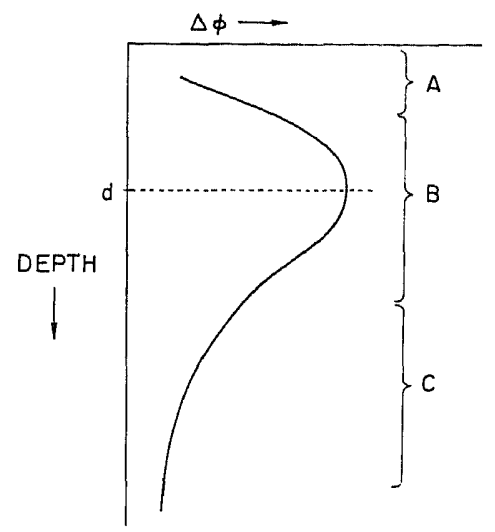

Fig. 1. Qualitative plot of the porosity change required to produce undersaturation vs. depth.

which undersaturation is much more difficult to achieve. Since $\Delta \phi / \phi$ needed to achieve undersaturation increases with depth, a constant percentage porosity increase may cause undersaturation, with resulting velocity anomaly, only at shallow depths. Although we do not know the actual distribution of dilatant strains in the crust, the above analysis nevertheless suggests that certain regions may be more susceptible to velocity anomalies than others. A closer look will verify this, and establish the actual depth and strain involved.

We take a very simple model of the crust. Let the lithostatic pressure gradient equal $300 \mathrm{bars} / \mathrm{km}$, the normal hydrostatic pore pressure gradient equal $100 \mathrm{bars} / \mathrm{km}$, and the temperature gradient equal $30^{\circ} \mathrm{C} / \mathrm{km}$. Let the crust be represented by Westerly granite, with known porosity as a function of confining pressure from BRACE et al. (1965). Assuming that porosity depends only on effective confining pressure (confining pressure minus pore pressure), Fig. 2 shows porosity vs. depth in the crust

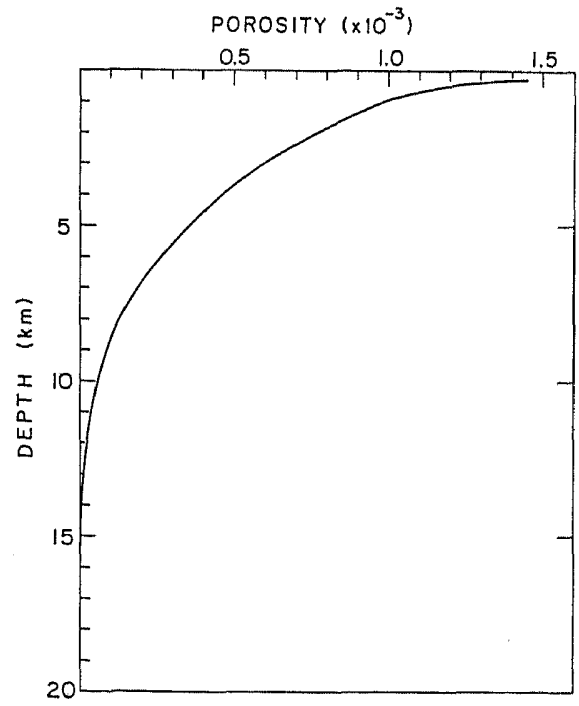

Fig. 2. Porosity vs. depth based on Westerly granite model. 
for this model. This is microcrack porosity. BRACE (1975) points out that a roughly constant amount of pore porosity is also present at all depths. We will ignore this for the present and discuss its consequences later.

It is not totally unambiguous how to intepret the term 'undersaturation.' For our purposes, and where pressure-temperature conditions allow, we assume that undersaturation occurs when vapor first begins to form. We then take the bulk modulus of the pore fluid to be that of vapor at that pressure and temperature (KENNEDY and Holzer, 1966; Keenan et al., 1969). Beyond the critical point (below $\sim 12 \mathrm{~km}$ in this model) we assume that undersaturation occurs when pore fluid compressibility equals $1 \mathrm{kbar}^{-1}$. This is a somewhat arbitrary assumption, but our results do not depend strongly upon it. Anderson and Whitcomb (1973) show that there is no significant change in $V_{p} / V_{s}$ as compressibility increases above $1 \mathrm{kbar}^{-1}$. With this model we can find the porosity increase $(\Delta \phi)$ necessary to achieve undersaturation vs. depth, shown in Fig. $3 \mathrm{~A}$. This shows that the dilatant strain required to cause undersaturation is small, and hence easy to achieve, at shallow and deep parts of the crust. In the middle $(\sim 3$ to $10 \mathrm{~km})$ there is a region in which undersaturation is more difficult to achieve. Figure 3B combines Figs. 2 and $3 \mathrm{~A}$ to show percentage porosity change. Although we do not know the actual distribution of dilatant strains in the crust, Figs. $3 \mathrm{~A}$ and $3 \mathrm{~B}$ suggest that certain regions may be more susceptible than others to undersaturation and a resulting velocity anomaly.

A possible added constraint here would be the amount of energy per unit volume required to produce the dilatant strain needed for undersaturation. A lower limit on this is the energy needed to expand the rock against the effective confining pressure. As a first approximation we can assume that effective pressure is constant while the rock is dilating. The energy per unit volume, $W$ is then (HANKs, 1974)

$$
W=\left(P_{c}-P_{p}\right) \Delta \phi,
$$

where $P_{c}$ is confining pressure, $P_{p}$ is pore pressure and $\Delta \phi$ is the porosity increase.

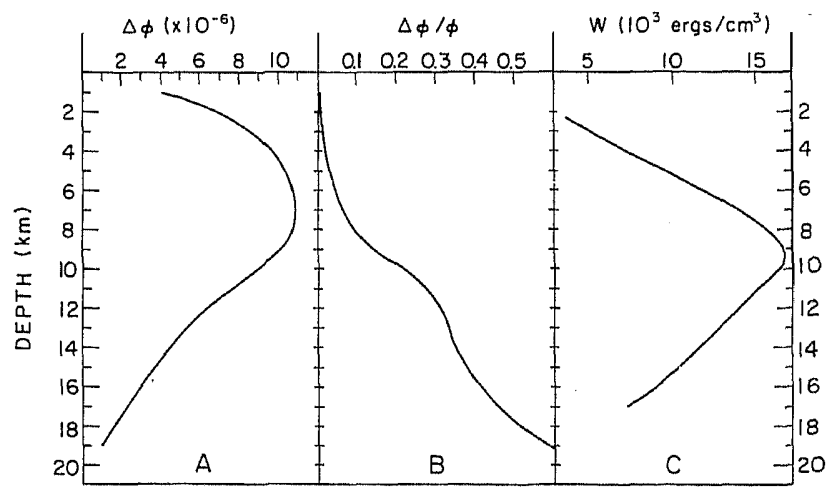

Fig. 3. (A) Quantitative plot of the porosity change required to produce undersaturation vs. depth. (B) Percentage porosity change required to produce undersaturation. (C) Energy required to produce undersaturation. 
Letting $\left(P_{c}-P_{p}\right) / z$ equal 200 bars $/ \mathrm{km}$ and with $\Delta \phi$ given in Fig. $3 \mathrm{~A}, W$ is shown in Fig. $3 \mathrm{C}$. Note the maximum energy required at about $10 \mathrm{~km}$. If available energy is a determining factor for undersaturation, we might again expect to find a depth dependence for velocity anomalies. We must note that these energy requirements may not constrain the problem at all. Increasing confining pressure at depth allows higher shear stresses to develop, so the energy needed for undersaturation may be available at all depths. Regardless of such uncertainties, Figs. $3 \mathrm{~A}$ and $3 \mathrm{C}$ imply that undersaturation, and therefore the onset of velocity anomalies, may be more likely to occur in shallow and deep regions than an intermediate depths. However, as will be shown in the next section, the low porosity at depth would have to be increased by a factor of 10 or more to create velocity anomalies comparable to those at shallow depths. This would essentially eliminate the apparently favorable deep region of Figs. $3 \mathrm{~A}$ and $3 \mathrm{C}$.

\section{Analysis: Velocity Anomalies}

The uncertainties of crustal parameters such as porosity, pore pressure, crack aspect ratios and elastic moduli, as well as of the dilatant behavior of rock under various pressure, temperature and strain rate conditions make it impossible to accurately calculate velocity anomalies. Nevertheless, we can attempt to estimate the effect of varying certain parameters and try to gain an idea of how velocity anomalies may vary with depth in the crust. We begin with the crustal model described earlier: lithostatic pressure gradient of $300 \mathrm{bars} / \mathrm{km}$, pore pressure gradient of $100 \mathrm{bars} / \mathrm{km}$, temperature gradient of $30^{\circ} \mathrm{C} / \mathrm{km}$, and porosity as in Fig. 2. We take a constant crack aspect ratio of 0.005 , rock matrix bulk and shear moduli of 500 and $250 \mathrm{kbars}$, respectively, and fluid bulk modulus equal to vapor bulk modulus if any vapor is present.

From the tables of KenNEDY and Holzer (1966) we calculate the bulk modulus of the pore fluid in this model, and then using equations derived by WALSH (1969) we calculate effective bulk and shear moduli for the fluid saturated rock as a function of depth. With these we determine $V_{p} / V_{s}=(K / \mu+4 / 3)^{1 / 2}$. A dilatant porosity increase in then applied to the model which creates a new distribution of pore fluid bulk modulus. The ratio $V_{p} / V_{s}$ is now re-calculated and the velocity anomaly $\mathcal{A}\left(V_{p} / V_{s}\right)$, is found. Since actual dilatant strain distributions prior to earthquakes are unknown, we have assumed a variety of porosity increases including constant percentage and constant magnitude increases. These strain distributions are not meant to coincide with actual crustal strain distributions prior to earthquakes, but are chosen to allow us to estimate the potential for changes in $V_{p} / V_{s}$. The resulting velocity anomalies are plotted vs. depth in Fig. 4A. In all cases, $V_{p} / V_{s}$ decreases. Line (1) in Fig. 4 represents a $25 \%$ porosity increase. As shown in Fig. 3B, undersaturation is achieved to a depth of $10 \mathrm{~km}$, yet the velocity anomaly in Fig. 4A falls off by a factor of two at $3 \mathrm{~km}$ and is negligible at $9 \mathrm{~km}$. This is the result of the very low porosity at depth. Increasing porosity by 5 or $50 \%$ gives almost no change from line (1). Next we alter 


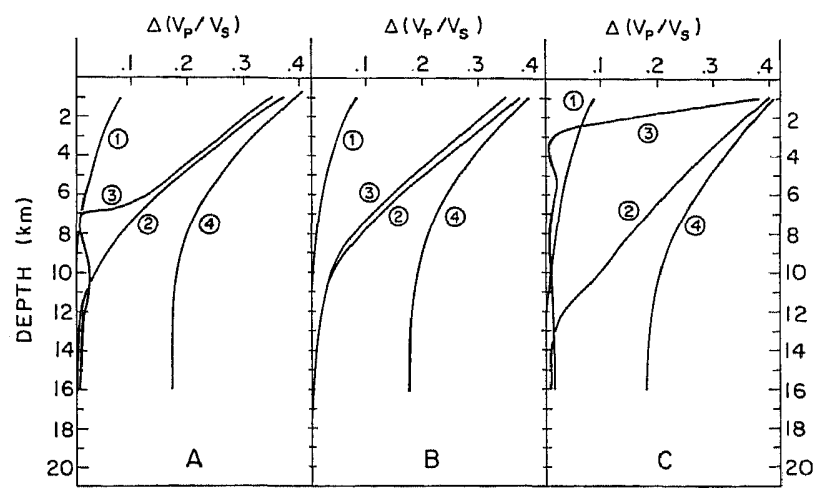

Fig. 4. Calculated $V_{p} / V_{s}$ changes for specified dilatant porosity increases.

Numbers refer to text. (A) Basic pressure-temperature crustal model.

(B) Temperature gradient decreased to $15^{\circ} \mathrm{C} / \mathrm{km}$. (C) Pore pressure gradient increased to $150 \mathrm{bars} / \mathrm{km}$.

our crustal model by increasing the initial, saturated porosity by a factor of 10 . This may better represent typical crust in many areas and it will illustrate the effect of porosity in our calculations. This change gives about $1 \%$ porosity near the surface. Line (2) shows the $V_{p} / V_{s}$ anomaly caused by $25 \%$ porosity increase of this higher porosity model. We now see substantial change to $11 \mathrm{~km}$, although it falls off by a factor of two at $5 \mathrm{~km}$. Line (3) represents a uniform increase of porosity by dilatancy of 0.0001 (roughly $1 \%$ of surface porosity). We now get an intermediate zone of negligible change with shallow and deep zones of larger change. Again, the anomaly decreases by $50 \%$ at $5 \mathrm{~km}$. Line (4) represents a uniform increase of porosity of 0.005 , which, though too large for the entire crust, because of uplift constraints, provides an upper limit. We now have undersaturation everywhere and the anomaly decreases with porosity. In each case so far we see that the potential for velocity changes decreases with depth, with the upper 4 or $5 \mathrm{~km}$ being the most favorable.

A different initial temperature gradient and/or pore pressure gradient will affect the initial bulk modulus of the fluid, and higher pore pressure will also increase the initial porosity. We can alter our crustal model to briefly examine these effects. First we decrease the temperature gradient from 30 to $15^{\circ} \mathrm{C} / \mathrm{km}$ and impose the same porosity changes as before. Figure $4 \mathrm{~B}$ shows the resulting velocity anomalies with lines numbered as in Fig. 4A. The anomalies are slightly large and extend to slightly greater depth, but there are no significant changes. The lower temperatures allow undersaturation with a smaller porosity increase, and this has removed the intermediate saturated zone in line (3) that appeared in Fig. 4A. To examine the affect of pore pressure, we now take our original crustal model and increase the pore pressure gradient to $150 \mathrm{bars} / \mathrm{km}$ (from $100 \mathrm{bars} / \mathrm{km}$ ). Velocity anomalies for this model are shown in Fig. $4 \mathrm{C}$ with lines corresponding to the same porosity changes as in Figs. 4A and 4B. Lines (1), (2), and (4) show slight increases due to the larger porosity. Line (3) is now cut off at about $3 \mathrm{~km}$ because a uniform increase of porosity of 0.0001 is no longer sufficient to achieve undersaturation below this 
depth. High pore pressures require larger porosity changes to achieve undersaturation, but when undersaturation does occur, the velocity anomaly will be slightly larger.

Some of the approximations we have made deserve a closer look. Crack aspect ratio has been shown to have a significant effect on wave velocities in rock (WALSH, 1969; Nur and Simmons, 1969; O'ConNell and Budiansky, 1974). While aspect ratio will not affect the occurrence of undersaturation, it will affect the magnitude of the velocity anomalies. We looked into this by reducing our constant aspect ratio from $5 \times 10^{-3}$ to $10^{-5}$ in our basic crustal model. The velocity anomaly for a $25 \%$ porosity increase went from 0.67 at $1 \mathrm{~km}$ depth to 0.44 at $10 \mathrm{~km}$, so the effect of a lower aspect ratio increases with depth (compare to Fig. 4A, line (2)). However, as HADLY (1976) points out, average aspect ratio should increase with depth in the crust as confining pressure closes flat cracks and leaves round pores relatively unchanged. Aspect ratios increasing with depth will have the net effect of increasing the anomalies at shallow depth in Fig. 4 and reducing the anomalies at greater depth.

In our crustal models we have not included pore porosity which takes the form of large aspect ratio voids in rock. BRACE (1975) has estimated pore porosity to be on the order of 0.001 for many rocks and independent of depth. Our results would not be significantly altered if we had considered this pore porosity. At shallow depths the low aspect ratio crack porosity, of comparable magnitude (or greater), will have a much greater effect on velocity than the high aspect ratio pore porosity. It will slightly increase the dilatant strain required for undersaturation. At greater depths the pore porosity will have a greater relative effect on velocities because the net porosity increase is significant, but the high aspect ratios should keep the effect small. However, this additional porosity at depth will significantly increase the dilatant porosity increase required for undersaturation. Therefore, while the affects of pore porosity are somewhat variable with depth, it appears that the net effect will reinforce the results arrived at above, namely, that the potential for velocity anomalies decreases with depth.

While our assumption of a hydrostatic pore pressure gradient seems reasonable, it conflicts somewhat with the conclusions of HANKS (1974), BraCE (1975), BOOKER (1975) and ANDERSON and WHitcomb (1975), who suggest that substantially lower pore pressures may exist at depth. If this is so, then the pore fluid at depth will be closer to the liquid-vapor transition pressure than we have assumed, and undersaturation will be achieved with smaller porosity increases than we have calculated. The smaller porosity increases will create correspondingly smaller velocity anomalies and so we again arrive at the conclusion that the largest velocity anomalies will be found at shallow depths (assuming undersaturation occurs everywhere). It is, of course, possible to conceive of pore pressure and dilatant strain distributions that will cause undersaturation only at great depths. However, this would severely limit the applicability of the dilatancy-diffusion theory unless such crustal conditions could be shown to be widespread in regions of seismic activity.

The point was made by HADLEY (1975) that if the earth's surface can be 
considered a fluid source, then undersaturation cannot occur in the upper $6 \mathrm{~km}$ of the crust. This would eliminate the region we have shown to have the greatest potential for velocity anomalies. It is not immediately clear when and where the earth's surface acts as a fluid source, but if it is a common feature then dilatancy induced velocity anomalies may be quite difficult to observe. It is important to note, however, that this places no constraints on the occurrence of dilatancy in the crust. The various earthquake precursors other than velocity that have been linked to dilatancy (ScHolz et al., 1973) may still be observable.

\section{Field Evidence}

Results of several field studies are somewhat variable and are of little help in evaluating our results. NERSESOv et al. (1971) reported velocity anomalies based on ray paths within the upper $10 \mathrm{~km}$ of the crust at Garm. For the 1972 earthquake at Bear Valley, Cal., a number of studies (BAKun et al., 1973; MCEvilly and JoHnson, 1973, 1974; Robinson et al., 1974; Cramer and KovaCH, 1975) indicate that an anomalous zone was highly localized and confined to the upper 5 or $10 \mathrm{~km}$ of the crust. ANDERson and Whitcomb (1973) imply that the upper $20 \mathrm{~km}$ of the crust was dilatant prior to the San Fernando earthquake.

The results reported by AgGarwal et al. (1973) for Blue Mountain Lake and TALWANI et al. (1976) for South Carolina are particularly interesting. In both places precursory velocity anomalies were reported for small earthquakes $(M \sim 3)$ at shallow depths. Our results suggest that small earthquakes would have the best chance of creating velocity anomalies in the upper few kilometers of the crust. However, both locations were near bodies of water (Blue Mountain Lake and Lake Jocassee) that should act as fluid sources in the sense suggested by HADLEY (1975). It is very difficult to see how undersaturation could have occurred in either location. The opening of new, dry cracks rather than the enlargement and undersaturation of existing cracks has been suggested as a possible alternative (Nur, 1972; HADLEY, 1975) but it seems unlikely that this mechanism could maintain undersaturation on the required time scale if the other mechanism could not. Therefore, dilatancy, as now understood, does not seem able to explain the reported anomalies in these two similar locations.

\section{Conclusions}

Simple considerations of crustal porosity and pore fluid compressibility imply that observable velocity precursors caused by dilatancy are more likely to occur within the upper 3 to $5 \mathrm{~km}$ of the crust than at depth. Dilatant deformation throughout the crust is likely to produce only localized velocity anomalies-only in those regions where undersaturation actually occurs. At shallow depths pore fluid has low compressibility and so requires a small porosity increase to produce undersaturation, yet the effective porosity is large enough so that once undersaturation 
has occurred the resulting velocity anomaly will be observable. At depths below $10 \mathrm{~km}$ the effective porosity may be too small for significant velocity anomalies to develop.

While shallow regions of the crust have the greatest potential for velocity anomalies resulting from dilatancy, in some areas this may be out-weighed by a fluid supply from the surface that prevents undersaturation. We conclude that in regions where the surface is not a fluid source, velocity precursors are most likely to be found in the upper parts of the crust. In regions where the surface is a fluid source, observable velocity anomalies should not be expected on the basis of dilatancy-diffusion. Another (perhaps related) mechanism may be needed to explain the observations at Blue Mountain Lake and South Carolina.

We emphasize, also, that dilatancy does not guarantee an observable velocity anomaly. Large velocity changes require undersaturation which is dependent on several crustal parameters. This in no way limits the value of dilatancy for explaining other effects associated with earthquakes such as surface uplift, resistivity changes, radon emission, or well-level fluctuations.

This study was supported by the U.S. Geological Survey, contract No. USDI 14-08-0001-14566. The views and conclusions contained in this document are those of the authors, and do not represent official policies of the United States government.

\section{REFERENCES}

Aggarwal, Y.P., L. R. Sykes, J. Armbruster, and M. L. Sbar, Premonitory changes in seismic velocities and prediction of earthquake, Nature, 241, 101-104, 1973.

Allen, C. R. and D. V. Helmberger, Search for temporal changes in seismic velocities using large explosions in Southern California, in Proceedings of the Conference on Tectonic Problems of the San Andreas Fault System, Stanford Univ. Publ. Geol. Sci. 13, edited by R. L. Kovach and A. Nur, pp. 436-445, 1973.

Anderson, D. L. and J. H. Whitcomb, The dilatancy diffusion model of earthquake prediction, in Proceedings of the Conference on Tectonic Problems of the San Audreas Fault System, Stanford Univ. Publ. Geol. Sci. 13, edited by R. L. Kovach and A. Nur, pp. 417-426, 1973.

Anderson, D. L. and J. H. Whitcomb, Time-dependent seismology, J. Geophys. Res., 80, 1497-1503, 1975.

Bakun, W. H., R. M. Stewart, and D. Tocher, Variations in $V_{p} / V_{s}$ in Bear Valley in 1972, in Proceedings of the Conference on Tectonic Problems of the San Andreas Fault System, Stanford Univ. Publ. Geol. Sci. 13, edited by R. L. Kovach and A. Nur, pp. 453-462, 1973.

Booker, J. R., Dilatancy and crustal uplift, Pageoph, 113, 119-125, 1975.

Boore, D. M., A. G. LINDH, T. V. MCEviLly, and W. W. Tolmachoff, A search for travel-time changes associated with the Parkfield, California, earthquake of 1966, Bull. Seismol. Soc. Am., 65, 1407-1418, 1975.

Brace, W. F., Dilatancy-related electrical resistivity changes in rocks, Pageoph, 113, 207-217, 1975.

BRACE, W. F., A.S. ORANGE, and T. M. MAdDEN, The effect of pressure on the electrical resistivity of water saturated crystalline rocks, J. Geophys. Res., 70, 5669-5678, 1965.

BRACE, W. F., B. W. PAUlding, Jr., and C. SCHOlz, Dilatancy in the fracture of crystalline rocks, J. Geophys. Res., 71, 3939-3953, 1966.

BRADY, B. T., Theory of earthquakes, Pure Appl. Geophys., 112, 701-726, 1974.

CRAMER, C., Teleseismic travel time residuals applied to the question of P-velocity changes preceding 
earthquakes in central and northern California, Ph. D. thesis, Dept. of Geophysics, Stanford Univ., 1976.

Cramer, C. H. and R. L. KovaCH, Time variations in teleseismic residuals prior to the magnitude 5.1 Bear Valley earthquake of February 24, 1972, Pageoph, 113, 281-292, 1975.

Gladwin, M. T. and F. D. STACEY, Ultrasonic pulse velocity as a rock stress sensor, Tectonophysics, 21, 39-45, 1974.

HADLEY, K., Laboratory investigation of dilatancy and motion on fault surfaces at low confining pressures, in Proceedings of the Conference on Tectonic Problems of the San Andreas Fault System, Stanford Univ. Publ. Geol. Sci. 13, edited by R. L. Kovach and A. Nur, pp. 427-435, 1973.

HADLEY, K., Comparison of calculated and observed crack densities and seismic velocities in Westerly granite, J. Geophys. Res., 81, 3484-3494, 1976.

Hadley, L., $V_{p} / V_{s}$ anomalies in dilatant work samples, Pageoph, 113, 1-23, 1975.

HANks, T. C., Constraints on the dilatancy-diffusion model of the earthquake mechanism, J. Geophys. Res., 79, 3023-3025, 1974.

Keenan, J. H., F. C. Keyes, P. G. Hrll, and J. G. Moore, Steam Tables, John Wiley, New York, 1969.

Kennedy, G. C. and W. T. Holzer, in Handbook of Physical Constants, Geol. Soc. Am. Mem. 97, edited by S. P. Clark, Jr., 587 pp., 1966.

MCEvilly, T. V. and L. R. Johnson, Earthquakes of strike-slip type in central California: Evidence on the question of dilatancy, Science, 182, 581-584, 1973.

McEvilly, T. V. and L. R. JoHnson, Stability of $P$ and $S$ velocities from central California quarry blasts, Bull. Seismol. Soc. Am., 64, 343-353, 1974.

Myachkin, V.I., W. F. Brace, G. A. Sobolev, and J.H. Dieterich, Two models for earthquake forerunners, Pure Appl. Geophys., 113, 169-181, 1975.

Nersesov, I. L., A. N. Semenov, and I. G. Simbireva, Space-time distribution of the travel-time ratios of transverse and longitudinal waves in the Garm area, in The Physical Basis of Foreshocks, Nauka Publ., 1969.

Nersesov, I. L., A. N. Semenov, and I. G. Simbereva, Space time distribution of the travel time ratios of transverse and longitudinal waves in the Garm region, in Experimental Seismology, edited by M. A. Sadovsky, pp. 334-345, Sci. Publ. House, Moscow, 1971.

Nur, A., Dilatancy, pore fluids and premonitory variations in $T_{s} / T_{p}$ travel times, Bull. Seismol. Soc. Am., 62, 1217-1222, 1972 .

Nur, A. and G. Simmons, The effect of saturation on velocity in low porosity rocks, Earth Planet. Sci. Lett., 7, 183-193, 1969.

O'Connell, R. and B. Budiansky, Seismic velocities in dry and saturated cracked solids, J. Geophys. Res., 79, 5412, 1974.

Robinson, R., R. L. Wesson, and W. L. Ellsworth, Variation of P-wave velocity before the Bear Valley, Ca., earthquake of 24 January 1972, Science, 184, 1281-1283, 1974.

Scholz, C. H., L. R. Sykes, and Y. P. Aggarwal, Earthquake prediction: A physical basis, Science, 181, 803, 1973.

SEMENOV, A. M., Variations in the travel-time of transverse and longitudinal waves before violent earthquakes, Bull. Acad. Sci. USSR, Phys. Solid Earth, 3, 245-248, 1969.

SNOw, D. T., Rock fracture spacings, openings and perosities, J. Soil Mech. Found. ASCE, 94, 73-91, 1968.

Stuart, W, D., Diffusionless dilatancy model for earthquake precursors, Geophys. Res. Lett., 1, 261264, 1974.

Talwani, P., D. Stevenson, J. Chiang, and D. Amick, The Jocassee Earthquakes, a preliminary report, Third technical report, Contract No. 14-08-0001-14533, U.S. Geol. Survey, 1976.

WALSH, J. B., New analysis of attenuation in partially melted rock, J. Geophys. Res., 74, 4333-4337, 1969.

Whitcomb, J. H., J. D. GARMANY, and D. L. ANDERSON, Earthquake prediction: Variation of seismic velocities before the San Fernando earthquake, Science, 180, 632-635, 1973. 